\title{
Monitoramento e avaliação do risco de contaminação por pesticidas em água superficial e subterrânea na região de Guaíra ${ }^{(1)}$
}

\author{
Heloisa Ferreira Filizola(2), Vera Lúcia Ferracini(2), Luís Marcelo Aguiar Sans ${ }^{(3)}$, \\ Marco Antônio Ferreira Gomes ${ }^{(2)}$ e Celso João Alves Ferreira(4)
}

Resumo - O objetivo deste trabalho foi determinar os níveis de ocorrência de pesticidas em água, tendo em vista preservar a água de contaminação por esses produtos na região de Guaíra, SP. A hipótese foi que o uso intensivo de pesticidas nessa região propiciaria a contaminação das águas superficiais e subterrâneas por seus resíduos. Para a caracterização das propriedades, das características e da dinâmica da água do solo, foi selecionada a Fazenda Macaúba por possuir relevo e solos característicos da região. Aproximadamente $80 \%$ da área da fazenda é constituída por Latossolo Vermelho distroférrico típico (LVdf), profundo. As áreas cultivadas apresentam um horizonte superficial (Ap) completamente desprovido de sua estrutura natural e, abaixo deste, um horizonte compactado, ambos frutos das práticas agrícolas. Durante dois anos e meio realizou-se o monitoramento do Ribeirão do Jardim que abastece a cidade de Guaíra, bem como de um de seus afluentes e da água subterrânea proveniente do Aqüífero Guarani, à procura de pesticidas. A água superficial foi coletada de $21 \mathrm{em} 21$ dias e a subterrânea, no início e no final do período monitorado (dois anos e meio). Os produtos monitorados, trifluralina, endosulfan, lambda cialotrina, dicofol (4,4 diclorobenzofenona), captan, metil paration, clorotalonil e clorpirifós, foram selecionados a partir de um levantamento dos pesticidas utilizados em quatro áreas agrícolas localizadas na bacia do Ribeirão do Jardim e em razão da efetividade de um método de análise de resíduos múltiplos para sua quantificação. Os resultados analíticos indicaram que não houve contaminação da água subterrânea, mas que ocasionalmente houve contaminação direta das águas de superfície. A não-contaminação da água subterrânea devese principalmente às características dos Latossolos, como sua grande espessura, sua textura argilosa e sua grande capacidade de armazenamento de água.

Termos para indexação: irrigação, infiltração, resíduos de pesticida, propriedades físico-químicas do solo.

Monitoring and evaluation of the risk of contamination by pesticide in surface water and groundwater in the Guaíra region, São Paulo, Brazil

\begin{abstract}
The objective of this work was to determine the level of occurrence of pesticides in water, with the purpose of preserving from contamination risk by these pesticides the potable water of the region of Guaíra, SP, Brazil. Preliminary hypothesis was that the intensive use of pesticide in the Guaíra region is an important factor in the potential contamination of the surface water and groundwater. To identify physical properties and water dynamics in soil, the Fazenda Macaúba was selected because of its soil and topography typical of the region. About $80 \%$ of the soil of the farm is Oxisol. The plowed layer of the soil has no natural structure and below it there is a compacted layer, both of which derived from agricultural activities. With the goal to evaluate the risk of contamination, the Jardim river, one of its tributary and the groundwater of the Guarani Aquifer were monitored for 2.5 years. The pesticides which were used for the irrigation activities (trifluralin, endosulfan, lambda cyhalothrin, dicofol (4,4 dichlorobenzofenone), captan, parathion-methyl, chlorothalonil and chlorpyriphos) were searched for. Water was analyzed by multiresidue method and the results of this study showed that there is not contamination, except by direct of the surface water. The absence of water contamination is interpreted in relation to the structural characteristics of the soils like thickness, grain size, and field capacity.
\end{abstract}

Index terms: irrigation, infiltration, pesticide residues, soil chemicophysical properties.

(1) Aceito para publicação em 16 de julho de 2001

(2) Embrapa-Centro Nacional de Pesquisa de Monitoramento e Avaliação de Impacto Ambiental (CNPMA), Caixa Postal 69, CEP 13820-000 Jaguariúna, SP. E-mail: filizola@cnpma.embrapa.br, veraf@cnpma.embrapa.br, gomes@cnpma.embrapa.br

(3) Embrapa-Centro Nacional de Pesquisa de Milho e Sorgo, Caixa Postal 151, CEP 35701-970 Sete Lagoas, MG.

E-mail: 1sans@cnpms.embrapa.br

(4) Embrapa-CNPMA. In memorium. 


\section{Introdução}

A necessidade de fornecer alimentos à população torna indispensável a realização de controle das doenças, pragas e plantas invasoras, com a utilização de pesticidas que se destacam entre as principais formas de controle. O impacto das atividades agrícolas modernas sobre a qualidade da água subterrânea tornou-se conhecido em alguns países industrializados durante a década de 70 . Em particular, demonstrou-se a existência de altas taxas de lixiviação de nitrato e outros íons móveis em muitos solos submetidos ao plantio contínuo, sustentado por aplicações de grandes quantidades de fertilizantes inorgânicos e defensivos agrícolas (Foster et al., 1993).

Em razão do crescimento natural da população e da contaminação das águas por substâncias químicas, o suprimento de água potável e de boa qualidade nas áreas mais desenvolvidas torna-se cada vez mais difícil e de maior custo. A qualidade da água potável e a não-contaminação dos alimentos só pode ser assegurada através de programas de monitoramento ambiental, que poderão minimizar o risco de poluição.

Os países da Comunidade Européia consideram que a Concentração Máxima Admissível (CMA) de um pesticida individual na água potável é de $0,1 \mu \mathrm{g} \mathrm{dm}^{-3}$, sem, no entanto, ultrapassar $0,5 \mu \mathrm{g} \mathrm{dm}^{-3}$ quando se considera a soma de todos os pesticidas. Limites semelhantes são adotados por outros países, como Estados Unidos e Canadá (Carney, 1991).

$\mathrm{Na}$ avaliação da contaminação das águas superficiais, subsuperficiais e subterrâneas por fontes difusas, estão envolvidas as propriedades dos agentes químicos e as variáveis ambientais, como tipos de solo, declividade e clima (Somasundaram \& Coats, 1991). A contaminação da água por pesticidas pode ocorrer diretamente pela deriva das pulverizações aéreas, pela lixiviação através da água no solo, através da erosão dos solos e pelo descarte e lavagem de tanques e embalagens.

As características do solo interferem de maneira direta e indireta no comportamento dos pesticidas no solo. A quantidade de matéria orgânica, a textura e a estrutura, que resultam na porosidade de um solo, são fatores de extrema importância na determinação do comportamento dos agentes contaminantes no ambiente. Grande parte dos pesticidas são sorvidos pela matéria orgânica, impedindo que estes alcancem o lençol freático via percolação. A textura e a porosidade são determinantes na capacidade do solo em reter ou não a solução do solo (Khan, 1980).

Os pesticidas possuem propriedades, como meiavida do produto no solo $\left(\mathrm{DT}_{50}\right)$; coeficiente de adsorção à matéria orgânica no solo (Koc), e solubilidade, que interagem com as propriedades dos solos, tais como teor da matéria orgânica e propriedades hidráulicas (Goss, 1992). Segundo este autor, em solos orgânicos raramente ocorre perda de pesticida por lixiviação e pesticidas com Koc acima de $300 \mathrm{~mL} \mathrm{~g}^{-1}$ são fortemente adsorvidos pela matéria orgânica. Assim o potencial de perda de pesticidas pela lixiviação depende das características do pesticida, do solo, do clima e dos fatores de manejo.

O objetivo deste trabalho foi determinar os níveis de ocorrência de pesticidas em água, visando caracterizar o risco de contaminação por esses produtos na região de Guaíra, SP.

\section{Material e Métodos}

A área de trabalho foi o Município de Guaíra, que está localizado na porção norte do Estado de São Paulo, entre $20^{\circ} 7^{\prime} 22^{\prime \prime}$ e $20^{\circ} 27^{\prime} 30^{\prime \prime}$ S e 48 $38^{\prime} 46^{\prime \prime}$ e 48 $8^{\circ} 45^{\prime \prime} \mathrm{W}$, ocupando uma área de $1.241 \mathrm{~km}^{2}$. Geologicamente, a região de Guaíra está localizada sobre os basaltos da Formação Serra Geral, sobrepostos aos arenitos da Formação Botucatu que armazenam oAqüífero Guarani, a maior reserva de água subterrânea da América do Sul. Os solos predominantes são do tipo Latossolo Vermelho distroférrico (LVdf), Aluminoférrico (Lvaf) e Eutroférrico (LVef), seguidos, em área, pelo Nitossolo Vermelho distroférrico (NVdf) e Eutroférrico (NVef), pelo Latossolo Vermelho distrófico (LVd) e eutrófico (LVe) e pelo Neossolo Quartzarênico Órtico (Rqo). A espessura dos basaltos na área varia desde 500 a menos de 50 m, o que significa que, em muitos locais, o Aqüífero Guarani está muito próximo da superfície. O relevo da área é plano a suave ondulado, com declividade média de 5\%. O clima da região apresenta as seguintes médias anuais: pluviosidade de $1.300 \mathrm{~mm}$, concentrada nos meses de outubro a abril, temperatura de $24^{\circ} \mathrm{C}$ e umidade relativa de $64 \%$.

A agricultura é intensiva, irrigada por pivô central e tem como características o uso intensivo de calcário, fertilizantes e pesticidas, além do manejo da água, o que permite até 
cinco safras em dois anos, principalmente de feijão, soja, milho e tomate. No período seco, a lâmina da água de irrigação varia de 9,5 a $22,5 \mathrm{~mm}$, dependendo da umidade do solo e do estádio de desenvolvimento da cultura.

$\mathrm{Na}$ caracterização das propriedades, das características e da dinâmica da água do solo, foi selecionada a Fazenda Macaúba, por possuir relevo e solos característicos da região. Aproximadamente $80 \%$ da área da fazenda Macaúba é constituída por LVdf, profundo $(>8 \mathrm{~m}$ de espessura no topo dos interflúvios e nos $2 / 3$ superiores das vertentes), que pode gradar para o Latossolo Amarelo distroférrico (LAdf), na porção final das vertentes ( $<2 \mathrm{~m}$ de espessura). Existem também couraças ferruginosas espessas e níveis de concreções ferruginosas que são normalmente encontrados, aflorantes ou não, no final do terço inferior das vertentes próximas às cabeceiras dos cursos da água de primeira ordem. Nas proximidades das áreas de afloramento das couraças ferruginosas, ou do que delas restou, podem ser encontrados Cambissolos Háplicos (CX), utilizados normalmente como pastagens. Nas várzeas são encontrados os Gleissolos Háplicos (GX).

As áreas cultivadas apresentam um horizonte superficial (Ap) completamente desprovido de sua estrutura natural e, abaixo deste, um horizonte compactado, ambos frutos das práticas agrícolas. Este último encontra-se geralmente entre 20 e $40 \mathrm{~cm}$ de profundidade.

Como as características do solo interferem de maneira direta e indireta no comportamento dos pesticidas no solo, inicialmente foi feito o reconhecimento dos solos da microbacia selecionada e, em seguida, o estudo detalhado dos solos de uma vertente, já que a microbacia é homogênea quanto à distribuição dos solos. Esse levantamento possibilitou a localização dos pontos de avaliação das características hídricas do solo, que podem interferir na movimentação da água, principal meio de transporte dos pesticidas.

O estudo feito através de toposseqüências mostrou que, na escala da vertente, a drenagem passa de vertical a lateral (em direção ao córrego que drena a área) somente quando chega à alteração do basalto, constituída por uma argila mosqueada (verde, vermelha e preta) maciça. Os Cambissolos, restritos às áreas das couraças ferruginosas, apresentam pouco impedimento à circulação vertical da água, pois, mesmo quando contínua, as couraças ferruginosas apresentam-se extremamente fissuradas, permitindo assim que a drenagem vertical seja livre até a argila mosqueada. Já os Gleissolos apresentam restrições à percolação da água, por serem constituídos por argila maciça pouco permeável.

Tanto o LVdf como o LAdf são argilosos a muito argi$\operatorname{losos}(50$ a $70 \%$ de argila), mas devido a estrutura micro- agregada são solos extremamente porosos; a macroporosidade na área de mata está na faixa dos $40 \%$, enquanto na área agrícola varia de $16 \%$, nos horizontes compactados, a $29 \%$, no horizonte Ap. A microporosidade não apresenta grandes variações. A densidade do solo, nos horizontes compactados, sofre um aumento de aproximadamente $45 \%$ em relação às densidades da mata (Tabela 1).

Foi dada ênfase ao movimento interno da água no solo, pois, como a Fazenda Macaúba apresenta um terraceamento eficiente, somente em situações de chuvas excepcionais $\left(>100 \mathrm{~mm} \mathrm{~h}^{-1}\right)$ a dinâmica da água é predominantemente superficial. Para o conhecimento dos fluxos hídricos, foram feitas, ao longo da vertente monitorada, medidas de campo do potencial mátrico (Figura 1) e da taxa de infiltração da água no solo nos principais horizontes (Tabela 1) e coletadas as amostras necessárias às análises laboratoriais. O potencial mátrico foi avaliado a partir de seis baterias de tensiômetros: quatro sob o pivô de irrigação, uma na área de pasto não-irrigado e uma no topo, em uma área remanescente de cerrado. As baterias contavam com tensiômetros colocados nas profundidades de 15, 30, $60 \mathrm{e}$ $120 \mathrm{~cm}$. A leitura dos tensiômetros foi feita sempre 12 horas antes e 12 horas após a irrigação e de 12 a 24 horas após a chuva.

O potencial total da água no solo (Figura 1) apresenta variação muito grande entre a área irrigada por pivô central e as áreas não-irrigadas (mata e pasto). As baterias sob irrigação apresentaram muito menos sifonamento, e a variação do potencial total acompanhou a profundidade, ou seja, quanto maior a profundidade, maior a tensão da água no solo. Além disso, na área irrigada, a variação do potencial mátrico é muito pequena ao longo do ano.

As amostras de solo para a determinação da densidade, da porosidade (total, macro e micro), da umidade, das curvas de retenção da solução do solo, da capacidade de campo e da condutividade hidráulica foram coletadas nos horizontes A ou Ap, compactado e Bl. As trincheiras foram abertas na mata (topo), no início da vertente, na meiaencosta, e no terço final da vertente. A taxa de infiltração e a infiltração acumulada foram determinadas em áreas próximas às trincheiras e das baterias de tensiômetros Os parâmetros condutividade hidráulica, capacidade de campo, taxa de infiltração da água no solo, textura, porosidade e densidade dos solos foram analisados segundo Embrapa (1997). As medidas de condutividade hidráulica foram feitas em amostras com estrutura não deformada (colunas de $15 \mathrm{~cm}$ de altura por $10 \mathrm{~cm}$ de diâmetro), previamente saturadas por capilaridade e submetidas a uma carga hidráulica constante de $7 \mathrm{~cm}$, durante uma hora. A taxa de infiltração e infiltração acumulada foi avaliada pelo método do infiltrômetro de duplo cilindro, durante duas horas. 
O horizonte Ap, completamente desprovido de sua estrutura natural, e o horizonte compactado têm funcionamentos muito diferenciados. No primeiro, dado o novo arranjo dos agregados ou a inexistência dos mesmos, a água percola facilmente. As taxas de infiltração, no LVdf, em Guaíra, decrescem de mais de $100 \mathrm{~mm} \mathrm{~h}^{-1}$ no horizonte Ap, até $12 \mathrm{~mm} \mathrm{~h}^{-1}$, nos horizontes compactados, retornando, no horizonte $\mathrm{Bl}$, aos valores anteriores. A condutividade hidráulica está em torno dos $550 \mathrm{~mm} \mathrm{~h}^{-1}$, na mata, enquanto no pivô ela não alcança $300 \mathrm{~mm} \mathrm{~h}^{-1}$ no horizonte $\mathrm{Bl}$, com redução de até oito vezes no horizonte compactado (Tabela 1).

A capacidade de campo está em torno de $23 \%$ e não apresenta grandes variações entre os horizontes e os diferentes pontos ao longo da vertente monitorada (Tabela 1).

A quantidade de carbono orgânico (CO), avaliada em quatro pontos ao longo da vertente monitorada, varia de $18,6 \mathrm{~g} \mathrm{dm}^{-3} \mathrm{em}$ superfície a $8,72 \mathrm{~g} \mathrm{dm}^{-3} \mathrm{em}$ profundidade (Tabela 1).

Os pontos escolhidos para as coletas de água para análise de resíduos de pesticidas foram selecionados por sua posição hierárquica na rede de drenagem do Ribeirão do Jardim, uma das fontes de abastecimento de água da cidade de Guaíra. As amostragens para a avaliação da contaminação das águas superficiais cobriram águas do córrego e da represa da Fazenda Macaúba, quatro pontos ao longo do
Ribeirão do Jardim. As amostras referentes às águas de superfície foram coletadas, diretamente ou com o auxílio de um amostrador de água do tipo Van Dorf, de $21 \mathrm{em}$ 21 dias, desde janeiro de 1995 até julho de 1997. As águas dos poços artesianos e semi-artesianos, provenientes do Aqüífero Guarani, foram coletadas duas vezes neste período.

Foram monitorados também dois poços existentes dentro da Fazenda Macaúba, um com $8 \mathrm{~m}$, localizado na sede baixa, e o outro com $14 \mathrm{~m}$ de profundidade, na sede alta; a diferença altimétrica entre os dois é de $50 \mathrm{~m}$. Para o monitoramento e amostragem do lençol subsuperficial foram instalados três piezômetros, nas proximidades da cabeceira do córrego da Fazenda Macaúba, a partir dos quais realizou-se o acompanhamento da oscilação do lençol e a amostragem da água. As coletas foram iniciadas em janeiro de 1996, prosseguindo até julho de 1997, com a mesma periodicidade das águas superficiais.

Os pesticidas analisados foram selecionados a partir de um levantamento de uso dos mesmos durante dois anos em quatro propriedades agrícolas localizadas na bacia do Ribeirão do Jardim. A escolha dos compostos a serem determinados, entre os cerca de doze princípios ativos diferentes utilizados em cada propriedade, foi em razão da efetividade de um método de resíduos múltiplos para sua quantificação. Foram selecionados pesticidas de persis-

Tabela 1. Taxa de infiltração (I), condutividade hidráulica avaliada em laboratório (K), macroporosidade (MAP), microporosidade (MIP), densidade do solo (Ds), capacidade de campo (CC), água disponível (AD) e carbono orgânico (CO) de solos representativos da fazenda Macaúba ${ }^{(1)}$.

\begin{tabular}{|c|c|c|c|c|c|c|c|c|}
\hline Perfil do solo & $\begin{array}{c}\mathrm{I} \\
\left(\mathrm{mm} \mathrm{h}^{-1}\right)\end{array}$ & $\begin{array}{c}\mathrm{K} \\
\left(\mathrm{mm} \mathrm{h}^{-1}\right)\end{array}$ & $\begin{array}{c}\text { MAP } \\
(\%)\end{array}$ & $\begin{array}{l}\text { MIP } \\
(\%)\end{array}$ & $\begin{array}{c}\text { Ds } \\
\left(\mathrm{g} \mathrm{cm}^{-3}\right)\end{array}$ & $\begin{array}{l}\mathrm{CC} \\
(\%) \\
\end{array}$ & $\begin{array}{l}\mathrm{AD} \\
(\%)\end{array}$ & $\begin{array}{c}\mathrm{CO} \\
\left(\mathrm{g} \mathrm{dm}^{-3}\right)\end{array}$ \\
\hline & \multicolumn{8}{|c|}{ Mata $^{(2)}$} \\
\hline Horizonte A & 223 & 519,4 & 40,30 & 33,61 & 0,94 & 25,50 & 6,84 & - \\
\hline \multirow[t]{2}{*}{ Horizonte B1 } & 123 & 532,1 & 38,08 & 39,88 & 0,98 & 26,83 & 8,93 & - \\
\hline & \multicolumn{8}{|c|}{ Ponto $1^{(3)}$} \\
\hline Horizonte A & 102 & & 25,50 & 35,47 & 1,11 & 23,54 & 8,67 & 18,8 \\
\hline Horizonte compactado & 14 & 28,3 & 16,55 & 38,62 & 1,38 & 23,72 & 4,56 & 14,7 \\
\hline \multirow[t]{2}{*}{ Horizonte $\mathrm{Bl}$} & 103 & 240,6 & 29,72 & 36,82 & 1,09 & 26,06 & 9,54 & 11,7 \\
\hline & \multicolumn{8}{|c|}{ Ponto $2^{(4)}$} \\
\hline Horizonte A & 113 & & 29,29 & 33,32 & 1,09 & 21,97 & 7,39 & 18,8 \\
\hline Horizonte compactado & 32 & 45,5 & 18,01 & 38,08 & 1,35 & 24,15 & 5,60 & 14,1 \\
\hline \multirow{2}{*}{ Horizonte Bl } & 133 & 266,1 & 31,59 & 36,82 & 1,07 & 24,62 & 9,00 & 12,3 \\
\hline & \multicolumn{8}{|c|}{ Ponto $3^{(5)}$} \\
\hline Horizonte A & 184 & & 23,65 & 36,35 & 1,14 & 23,63 & 7,95 & 18,8 \\
\hline Horizonte compactado & 12 & 33,4 & 18,93 & 37,66 & 1,42 & 22,04 & 5,00 & 14,7 \\
\hline Horizonte Bl & 150 & 264,4 & 30,75 & 37,26 & 1,09 & 24,28 & 8,77 & 8,8 \\
\hline
\end{tabular}

${ }^{(1)}$ Médias de cinco avaliações por ponto. (2)Mata: resto de cerrado no interflúvio. ${ }^{(3)}$ Ponto 1: LVdf sob pivô, localizado no início da vertente (4)Ponto 2: LVdf sob pivô, localizado na meia encosta. ${ }^{(5)}$ Ponto 3: LVdf localizado no terço final da vertente, no pasto. 

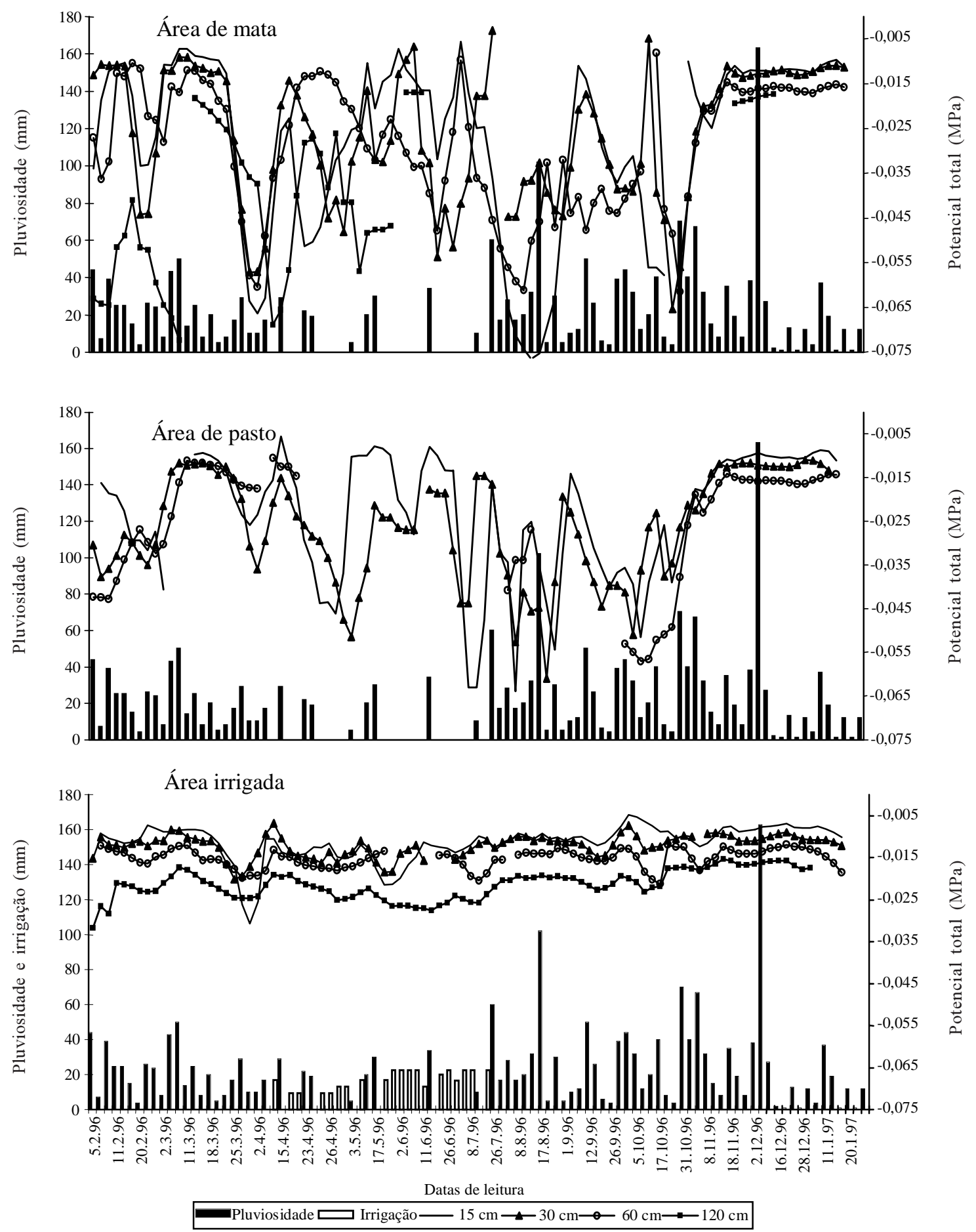

Figura 1. Potencial total de água no solo, pluviosidade e irrigação na área monitorada, na Fazenda Macaúba, em Guaíra, SP. A interrupção das linhas significa que houve sifonamento do tensiômetro. 
tência média como trifluralina, endosulfan (alfa e beta e seu metabólito endosulfan sulfato), lambda cialotrina e dicofol, do qual foi analisado seu metabólito 4,4 diclorobenzofenona, e pesticidas de persistência curta como captan, metil paration, clorotalonil e clorpirifós (Tabela 2).

A identificação e quantificação dos resíduos de pesticidas foram realizadas através de métodos cromatográficos. O método utilizado para análise dos resíduos de pesticidas foi o de Zavatti \& Abakerli (1999) modificado. As amostras de água, $0,5 \mathrm{~L}$, foram filtradas em membrana millipore $0,45 \mu \mathrm{m}$, passadas por cartuchos de Sep-Pack $\mathrm{C}_{18}$, precondicionados com hexano e acetona. Os pesticidas foram eluídos com 3,0 mL de hexano:acetona (1:1). O extrato obtido foi concentrado em rotavapor e analisado por um cromatógrafo gasoso equipado com detector de captura eletrônica (DCE) para os compostos organoclorados. Para o DCE foi utilizada a coluna HP $50(30 \mathrm{~m} \mathrm{x} 0,53 \mathrm{~mm} \mathrm{x}$ $0,22 \mu \mathrm{m})$. A programação da coluna foi: $185^{\circ} \mathrm{C}(3 \mathrm{~min})$,

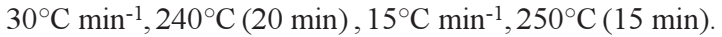

A área cultivada da Fazenda Macaúba é irrigada por quatro pivôs centrais, sendo que destes foi acompanhado aquele situado próximo à nascente do córrego, em sua margem esquerda (Tabela 3).

\section{Resultados e Discussão}

Não foram detectados resíduos dos compostos nas amostras de água do lençol subsuperficial (1 a $3 \mathrm{~m}$ ), nas águas de poços profundos (>100 m) e pouco profundos (8 a $50 \mathrm{~m}$ ), nos anos de $1996 \mathrm{e}$ de 1997.

Somente no ano de 1996, foram detectados, nas águas de superfície, resíduos de clorotalonil, 4,4 diclorobenzofenona, captan, endosulfan sulfato e lambda cialotrina (Tabela 4).
O clorotalonil foi detectado em maio de 1996. O 4,4 diclorobenzofenona e endosulfan sulfato foram detectados nos meses de março e abril de 1996, enquanto o captan foi detectado nos meses de março e maio, e a lambda cialotrina foi detectada no mês de abril. Todos esses compostos foram detectados em valores acima do máximo tolerável para água (Carney, 1991). O endosulfan sulfato, principal metabólito do endosulfan $\alpha$ e $\beta$, aparece em quantidade superior ao seu produto de origem (Tabela 4). Nos anos de 1995 e 1997, não foram detectados resíduos de nenhum dos pesticidas monitorados.

O endosulfan, apesar de não ser um produto receitado para o tomate e, portanto, não constar do levantamento feito, é utilizado clandestinamente e com muita freqüência nessa cultura.

O fato de terem sido encontrados resíduos de pesticidas nas águas superficiais, num único período do ano, foi questionado, e, à procura de respostas para tal fato, foi descoberto que, quando há interrupção da energia elétrica, os tanques de aplicação e por vezes as embalagens de agroquímicos são lavados nos córregos.

Como só as águas superficiais são episodicamente contaminadas (apesar do uso de pesticidas ser grande) e nunca nos dois anos e meio de monitoramento as águas subterrâneas, levantou-se a hipótese de que são as propriedades físicas dos Latossolos aliadas às características dos pesticidas monitorados que impedem que estes atinjam o lençol freático e mesmo o lençol subsuperficial pouco profundo (14 a $8 \mathrm{~m}$ de profundidade na área plantada). Além disso, como o teor de CO é baixo $\left(18,6 \mathrm{~g} \mathrm{dm}^{-3}\right)$, só uma pe-

Tabela 2. Características físico-químicas dos pesticidas monitorados ${ }^{(1)}$.

\begin{tabular}{|c|c|c|c|c|c|c|c|c|}
\hline Ingrediente ativo & Grupo químico & Utilização & $\begin{array}{c}\text { Pressão de } \\
\text { vapor } \\
(\mathrm{mm} \mathrm{Hg})\end{array}$ & $\begin{array}{c}\text { Solub. } \\
\text { água } \\
\left(\mathrm{g} \mathrm{m}^{-3}\right)\end{array}$ & $\begin{array}{c}\text { Koc } \\
\left(\mathrm{mL} \mathrm{g}^{-1}\right)\end{array}$ & $\begin{array}{l}\mathrm{DT}_{50} \text { solo } \\
\text { (dias) }\end{array}$ & $\begin{array}{c}\mathrm{K}_{\mathrm{H}} \\
\left({\mathrm{Pa} . \mathrm{m}^{3}}^{-1}\right) \\
\left.\mathrm{mol}^{-1}\right)\end{array}$ & $\begin{array}{c}\text { Kow } \\
\left(25^{\circ} \mathrm{C}\right)\end{array}$ \\
\hline Captan & Ftalimida & Fungicida & $8,0.10^{-8}$ & 5,1 & 200 & 2,5 & $3,2.10^{-3}$ & 610 \\
\hline Clorotalonil & Organoclorado & Fungicida & $0,001^{(2)}$ & 0,6 & 1.380 & 30 & 58 & 780 \\
\hline Clorpirifós & Organofosforado & Inseticida & $1,7.10^{-5}$ & 0,4 & 6.070 & 30 & 1,98 & 50.000 \\
\hline Dicofol & Organoclorado & Acaricida & $4,0.10^{-7}$ & 0,8 & $5.000^{(2)}$ & 45 & 2,4 & 19.000 \\
\hline Endosulfan & Organoclorado & Inseticida & $1,7.10^{-7}$ & 0,32 & 12.400 & 50 & $2,87 \cdot 10^{-2}$ & 58.307 \\
\hline Lambda-cialotrina & Piretróide & Inseticida & $1,5 \cdot 10^{-9}$ & 0,005 & 180.000 & 30 & $1,8.10^{-2}$ & $10^{7}$ \\
\hline Metil paration & Organofosforado & Inseticida & $1,5 \cdot 10^{-5}$ & 60 & 5.100 & 5 & $7,56 \cdot 10^{-6}$ & $10^{3}$ \\
\hline Trifluralina & Dinitroanilina & Herbicida & $1,1.10^{-4}$ & 0,3 & 8.000 & 60 & 4,02 & 118.000 \\
\hline
\end{tabular}

${ }^{(1)} \mathrm{Koc}$ : coeficiente de adsorção à matéria orgânica; $\mathrm{DT}_{50}$ : meia-vida do produto no solo; $\mathrm{K}_{\mathrm{H}}$ : constante de Henry; Kow: coeficiente de partição octanol-água. (2) Valor estimado. 
quena quantidade dos produtos aplicados será sorvido pela mesma

Estas características físicas refletem-se nas propriedades hídricas do solo. Segundo Veihmeyer \& Hendrickson (1931) e Seihmeyer \& Hendrickson (1949), a capacidade de campo é a quantidade de água retida pelo solo depois que o excesso tenha sido drenado, o que ocorre dois ou três dias depois de uma chuva ou irrigação em solos permeáveis de estrutura e textura uniformes, como é o caso dos Latossolos estudados. Coleman (1947) estabeleceu o valor do fim da drenagem livre em $-3,44 \mathrm{~m}$, que é o valor de $-30 \mathrm{kPa}$, o mais utilizado. Assim, na área irrigada (Figura 1), onde o potencial máximo foi aproximadamente $-30 \mathrm{kPa}$, pode-se afirmar que há drenagem livre praticamente todo o ano, ao menos nos primeiros $120 \mathrm{~cm}$ do solo

No período monitorado, a área sob o pivô recebeu $363,5 \mathrm{~mm}$ de água de irrigação, no período seco; a evapotranspiração da cultura do feijão é de $350,3 \mathrm{~mm}$ (Saad, 1991). Não há, portanto, no período seco, perda da água fornecida pelo pivô via percolação. Assim, neste período, o potencial de lixiviação dos pesticidas é praticamente nulo. Nos períodos chuvosos, quando a pluviosidade média está em torno de $900 \mathrm{~mm}$, o excedente de água é grande, permitindo, assim, que haja lixiviação dos agrotóxicos, mas apesar de a velocidade de infiltração ser alta, a capacidade de armazenamento de água pelo LV também é grande.

A análise da distribuição do potencial total, ao longo do ano, na área do pivô, mostra a tendência geral de um fluxo descendente, nos períodos chuvosos. No início da estação seca, mas por um período muito curto, o fluxo torna-se ascendente, havendo com a irrigação um retorno ao estado de fluxo descendente. As áreas de mata e de pasto mostram uma tendência de inversão de fluxo ligada à oferta de água e a resposta do potencial à chuva. Mas seja na área do pivô, seja nas áreas não irrigadas, o tempo de infiltração é alto, pois os tensiômetros mais profundos demoram pelo menos uma dezena de dias para retornarem a um potencial maior (Figura 1) e isto seria conseqüência da grande capacidade de armazenar água dos latossolos.

A análise da variação do potencial mátrico em relação à área irrigada e à área de pasto estão de acor- 
do com as condutividades hidráulicas encontradas, mas não para a área de mata. A explicação para a variação do potencial mátrico entre a área irrigada por pivô central e a área da mata talvez esteja na hipótese proposta por Souza \& Reichardt (1996), que para cada sistema de molhamento aplicado ao solo, em razão da distribuição da água no perfil, antes do molhamento, haverá diferentes interações entre o potencial da água e a umidade do solo, em relação ao fluxo de água descendente.

Apesar de a camada compactada ser uma degradação do solo, esta tem um papel importante na redução da infiltração, e portanto na lixiviação dos pesticidas, pois há uma redução de quase $50 \%$ dos macroporos no horizonte compactado. Kertzman (1989), trabalhando com os LV de Guaíra, constatou que os poros são afetados de maneiras diferentes pelo uso de maquinário: os poros intragregados $(<0,1 \mu$ de raio) não são perturbados pela compactação; os poros interagregados, de diâmetro compreendido entre $1 \mu$ e $10 \mathrm{~mm}$, apresentam redução de tamanho e do volume ocupado: o diâmetro médio se reduz à metade no horizonte compactado, enquanto a diminuição da porosidade interagregados é da ordem de 30\%. Chauvel et al. (1991) mostraram que esta degradação da estrutura é particularmente acentuada nos solos com mais de 50\% de argila. Esta redução da macroporosidade reflete diretamente na dinâmica da água no solo, como mostram os dados referentes à condutividade hidráulica e às taxas de infiltração (Tabela 1). A diminuição dos macroporos e a manutenção da microporosidade na camada compactada faz com que a água seja retida por uma pressão maior e, conseqüentemente, provoca diminuição da velocidade de infiltração da água.

Assim, mesmo os compostos que têm meia vida no solo $\left(\mathrm{DT}_{50}\right)$ longa, como a trifluralina, o endosulfan e o dicofol, ou aqueles com Koc muito baixo, como o Captan, degradam-se antes de atingir o lençol freático. O valor alto de Koc para a lambda cialotrina, mesmo com pouca quantidade de matéria orgânica, não permitiria que a mesma fosse lixiviada, sendo um argumento a mais a favor de contaminações acidentais por lavagem de tanques e embalagens no córrego.

Além disso, deve-se considerar na análise a influência da alta radiação solar na região, dado seu favorecimento à degradação dos pesticidas por fotólise, assim como a alta evaporação na região que poderá favorecer os processos de volatilização das moléculas. Desta forma, há a probabilidade de redução da meia vida destes compostos no solo em relação aos dados médios encontrados na literatura, podendo assim favorecer a dissipação dos compostos.

Tabela 4. Resultados das análises de pesticidas em amostras de água do córrego da Fazenda Macaúba, na região de Guaíra, SP, nas datas em que foram detectados (limite de detecção: $\left.0,2 \mu \mathrm{g} \mathrm{L}^{-1}\right)^{(1)}$.

\begin{tabular}{|c|c|c|c|c|c|c|c|c|c|c|}
\hline \multirow[t]{3}{*}{ Local $^{(2)}$} & \multicolumn{10}{|c|}{ Princípio ativo } \\
\hline & $\begin{array}{l}\text { Triflu- } \\
\text { ralina }\end{array}$ & $\begin{array}{l}\text { Cloro- } \\
\text { talonil }\end{array}$ & $\begin{array}{c}\text { Metil } \\
\text { paration }\end{array}$ & $\begin{array}{l}\text { Clorpi- } \\
\text { rifós }\end{array}$ & $\begin{array}{l}4,4 \text { dicloro- } \\
\text { benzofenona }\end{array}$ & $\begin{array}{l}\alpha \text {-endo- } \\
\text { sulfan }\end{array}$ & Captan & $\begin{array}{l}\beta \text {-endo- } \\
\text { sulfan }\end{array}$ & $\begin{array}{l}\mathrm{SO}_{4}^{-} \text {endo- } \\
\text { sulfan }\end{array}$ & $\begin{array}{l}\text { Lambda } \\
\text { cialotrina }\end{array}$ \\
\hline & \multicolumn{10}{|c|}{ - $\left(\mathrm{g} \mathrm{L}^{-1}\right)$} \\
\hline & & \multicolumn{9}{|c|}{$5 / 3 / 96$} \\
\hline CFM & nd & nd & nd & nd & nd & nd & nd & nd & nd & nd \\
\hline CFM & nd & nd & nd & nd & nd & nd & 0,78 & 0,2 & nd & nd \\
\hline \multirow[t]{2}{*}{ RJ } & nd & nd & nd & nd & 0,47 & nd & 1,29 & nd & 0,65 & nd \\
\hline & & \multicolumn{9}{|c|}{$16 / 4 / 96$} \\
\hline CFM & nd & nd & nd & nd & nd & nd & nd & nd & nd & nd \\
\hline CFM & nd & nd & nd & nd & nd & nd & nd & nd & nd & 0,2 \\
\hline \multirow[t]{2}{*}{ RJ } & nd & nd & nd & nd & 0,63 & nd & nd & nd & 0,76 & 5,66 \\
\hline & & \multicolumn{9}{|c|}{$28 / 5 / 96$} \\
\hline CFM & nd & 0,27 & nd & nd & 0,22 & nd & 0,31 & nd & nd & nd \\
\hline CFM & nd & nd & nd & nd & nd & nd & 0,7 & nd & nd & nd \\
\hline RJ & nd & nd & nd & nd & nd & nd & nd & nd & nd & nd \\
\hline
\end{tabular}

\footnotetext{
${ }^{(1)}$ nd: não detectado. ${ }^{(2)} \mathrm{CFM}$ : córrego da Fazenda Macaúba; RJ: Ribeirão do Jardim, à jusante da confluência deste com o córrego da Fazenda Macaúba
} 
O fato de só ter havido o acompanhamento das aplicações de pesticidas de somente um dos pivôs da fazenda, e os dados apresentados da Tabela 3 não terem auxiliado na explicação dos índices de pesticidas encontrados no córrego da Fazenda Macaúba e no Ribeirão do Jardim, não invalida a argumentação, pois como não foi encontrado, em momento algum, pesticida no lençol subsuperficial que alimenta o córrego, pode-se afirmar que a contaminação da água de superfície, quando houve, aconteceu por práticas incorretas.

\section{Conclusões}

1. Apesar do uso intensivo de pesticidas, a parte confinada do Aqüífero Guarani não está contaminada, principalmente devido às características físicas dos solos, como: grande espessura, textura argilosa, e grande capacidade de armazenamento de água.

2. Como os LVdf e os LVaf recobrem grande parte da região de Guaíra, os resultados obtidos têm significado regional.

3. A ocorrência ocasional de resíduos de pesticidas além do permitido pela legislação, nas águas superficiais, é conseqüência da lavagem de tanques de aplicação e de embalagens de pesticidas, pois o lençol pouco profundo não está contaminado.

4. A avaliação preliminar da possibilidade de contaminação por pesticidas das águas superficiais, subsuperficiais e subterrâneas de uma área agrícola pode ser feita a partir das características físicas dos solos, o que é vantajoso, dado o alto custo das análises de resíduos de pesticida.

\section{Agradecimentos}

Ao Dr. Terso Bento Junqueira, proprietário da Fazenda Macaúba, e à Prefeitura do Município de Guaíra, pelo apoio dado na execução deste trabalho.

\section{Referências}

CARNEY, M. European drinking water standards. Journal of American Water Works Association, Denver, v. 83, n. 6, p. 48-55, 1991

CHAUVEL, A.; GRIMALDI, M.; TESSIER, D. Changes in soil pore-space distribution following deforestation and revegetation: an example from the Central Amazon Basin, Brazil. Forest Ecology and Management, Amsterdam, v. 38 , p. $259-271,1991$
COLEMAN, E. A. A laboratory procedure for determining the field capacity of soils. Soil Science, Baltimore, v. 63, p. $277-283,1947$

EMBRAPA. Centro Nacional de Pesquisa de Solos (Rio de Janeiro, RJ). Manual de métodos de análise de solo Rio de Janeiro: Embrapa-SPI, 1997. 212 p

FOSTER, S.; VENTURA, M.; HIRATA, R. Poluição das águas subterrâneas: um documento executivo da situação da América Latina e Caribe com relação ao abastecimento de água potável. São Paulo: Instituto Geológico, 1993. $55 \mathrm{p}$

GOSS, D. W. Screening procedure for soils and pesticides for potential water quality impacts. Weed Technology, Lawrence, v. 6, p. 701-708, 1992

KERTZMAN, F. F. Modification de la structure et des propriétés physiques des couches superficielles d'un "Latossolo Roxo" (Guaíra, São Paulo, Brésil) soumis a une irrigation par aspersion. Rennes: Université Pierre et Marie Curie, 1989. 51 p. Diplôme d'Étude Agronomique.

KHAN, S. U. Pesticides in the soil environment. Amsterdam: Elsevier Scientific, 1980. 240 p

SAAD, A. M. Uso do tensiômetro no controle da irrigação por pivô central em cultura do feijoeiro Piracicaba: Esalq, 1991. 147 p.

SEIHMEYER, F. J.; HENDRICKSON, A. H. Methods of measuring field capacity and permanent wilting percentage of soils. Soil Science, Baltimore, v. 68, p. $75-95,1949$

SOMASUNDARAM, L.; COATS, J. R. Pesticide transformation products in the environment. In: SOMASUNDARAM, L.; COATS, J. R. (Ed.). Transformation products fate and significance in the environment. Washington: American Chemical Society, 1991. p. 2-9

SOUZA, L. D.; REICHARDT, K. Estimativas da capacidade de campo. Revista Brasileira de Ciência do Solo Campinas, v. 20, n. 2, p. 183-189, 1996.

VEIHMEYER, F. J.; HENDRICKSON, A. H. The moisture equivalent as a measure of the field capacity of soils. Soil Science, Baltimore, v. 32, p. 181-194, 1931.

ZAVATTI, L. M. S.; ABAKERLI, R. B. Resíduos de agrotóxicos em frutos de tomate. Pesquisa Agropecuária Brasileira, Brasília, v. 34, n. 3, p. 473-480, mar. 1999.

Pesq. agropec. bras., Brasília, v. 37, n. 5, p. 659-667, maio 2002 